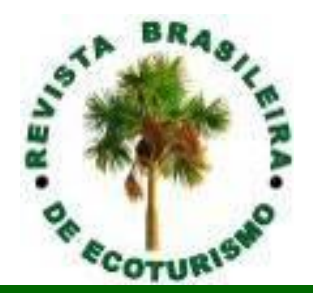

\title{
Aspectos da educação e da interpretação ambiental no Ecoturismo no Brasil
}

\section{Aspects of education and environmental interpretation in Ecotourism in Brazil}

\author{
César Floriano de Camargo, Silmar Cardoso Araújo Coelho
}

\begin{abstract}
RESUMO: O presente trabalho, tem por escopo, analisar a correlação das ações que devem coexistir para fins de um uso adequado e de sustentabilidade do meio ambiente. Desta forma, inegável é a necessidade de perpassar pelos caminhos da educação, seja esta formal ou não, bem como com a mudança de paradigmas culturais de certos povos e/ou regiões que, dado seus costumes ou por seu desconhecimento do espaço que sem preservação torna-se finito. O sistema capitalista que nos rodeia impõe a necessidade do ser humano gerar renda e riqueza e uma das maiores riquezas do nosso Brasil continental, é a natureza, exuberante em suas formas e sem sombra de dúvidas o país é detentor de uma considerável sociobiodiversidade, a qual é matéria prima para o implemento do turismo. Desta forma, o desenvolvimento com sustentabilidade dos espaços a serem desenvolvidos o ecoturismo devem sem sombra de dúvidas passar por estudos dos mais diversos, todos com o fito de conhecimento do espaço ambiental destinado ao turismo ecológico ou como alguns preferem ao ecoturismo. Desta forma SILVA, Edilson Adão Cândido da e Júnior, Laércio Furquim. Geografia em rede, $3^{\circ}$ ano. 2. edição. São Paulo: FTD,2016. (Coleção geografia em rede). NASCIMENTO, Júnio Batista do. Tocantins: história e geografia. Goiânia: Kelps, 2013. https://mundoeducacao.uol.com.br. Para se ter esclarecimento e conhecimento científico para melhor extrair do meio o que dele pode com o mínimo impacto, extrair, fazendo desta forma a melhor interpretação do espaço ambiental propício ao ecoturismo, deve-se seguir métodos e ações que sem sombra de dúvidas iniciam na educação.
\end{abstract}

PALAVRAS CHAVE: Educação; Interpretação; Meio Ambiente; Ecoturismo.

ABSTRACT: The present work aims to analyze the correlation of actions that must coexist for the purpose of an adequate use and sustainability of the environment. In this way, it is undeniable that there is a need to go through the paths of education, whether formal or not, as well as with the cultural paradigms of certain peoples and / or regions that, given their customs or their lack of knowledge of the space, is finite. The capitalist system that surrounds us imposes the need to have human beings generating income and wealth and one of the greatest riches of our continental Brazil is nature, exuberant in its forms and without a doubt holds a considerable socio-biodiversity, which is raw material for the implementation of tourism. In this way, the development with sustainability of the spaces has ecotourism has an undoubted potential to be studied with the aim of knowing the environmental space destined to ecological tourism or how some prefer, ecotourism. Thus, in order to have a clear understanding and scientific knowledge to better extract from the environment what it can offer, with the minimum impact, thus making the best interpretation of the environmental space that can lead to ecotourism, one must follow methods and actions that undoubtedly starts with education.

KEYWORDS: Education; Interpretation; Environment; Ecotourism. 


\title{
Introdução
}

Para fins perfunctórios a dar ao leitor uma breve introdução do presente trabalho, foi realizada uma revisão de literatura concernente ao assunto de que trata o tema deste trabalho. Esta revisão permeia o tema do trabalho, 'aspectos da educação e da interpretação ambiental no ecoturismo no Brasil'.

Desta forma, houve uma revisão integrativa da literatura para fins de subsidiar outros trabalhos e ações sobre os aspectos inerentes ao ecoturismo, bem como para despertar e debater a indiscutível importância da educação na seara do ecoturismo.

Assim, buscou-se doutrinas, obras e outros artigos que exemplificassem e descrevessem a importância de extrair da expressão 'ecoturismo' seu ímpar significado, aprimorando, assim a comunicação formal e informar com os agentes envolvidos em ações voltadas ao ecoturismo.

Para tanto, discorreu-se sobre os aspectos fundamentais e conceituais, para a melhor compreensão do termo 'ecoturismo' para fins de sua aplicabilidade em ações governamentais ou de iniciativa privada, sempre pautado pelo alicerce da boa educação voltada ao aprimoramento do ecoturismo.

\section{A Educação Ambiental e o desenvolvimento sustentável com foco no Ecoturismo no Brasil}

No Brasil o tema Educação Ambiental é bastante citado em meios de comunicações, livros, entre outros. Porém, ainda há muitas pessoas que não possuem o senso crítico em relação a conservação do meio ambiente.

A Educação Ambiental, numa perspectiva de formação crítica, requer a formação de educandos que saibam usar os recursos da natureza sem agravarem os impactos ambientais.

\begin{abstract}
A Educação Ambiental no Brasil apresentou-se em duas faces, a primeira como um modismo desenfreado e através do oportunismo, a segunda como uma opção pedagógica crítica aos modelos vigentes, a Educação Ambiental é uma das mais importantes exigências educacionais contemporâneas, explicando que não deve ser utilizada como a transmissão de conhecimento ambiental, mas buscando ampliar a participação política do cidadão, e deve ser inserida desde cedo, e com as crianças que temos a oportunidade de mudança de conceito a respeito de educação. Portanto, ela tem como intuito a consolidação da democracia, a solução dos problemas ambientais e a melhora da qualidade de vida partindo da ética e do diálogo entre gerações e culturas (BRANCALIONE, 2016, p.3).
\end{abstract}

Quando se fala em Educação Ambiental, destaca-se que não é apenas uma maneira de resolver certos problemas ambientais, mas também que deve-se criar nos educandos a percepção que pertencem ao meio natural para que se sintam parte de todo o processo. Desta forma, constrói-se um sentimento de pertencimento ao meio natural, cria-se a identidade cultural, e isso faz com que as pessoas mudem 
as formas de se inserir no meio natural e passem a trabalhar esses locais com o sentido de um desenvolvimento sustentável.

Segundo Brancalione (2016, p.8):

[...] É de extrema importância a exploração dos recursos naturais, através de projetos de aprimoramento em prol a Educação Ambiental. Se realizada uma análise do meio ambiente como biosfera, ou seja, existe vida em todos os sentidos, e a vivência de múltiplas espécies é uma interdependência das realidades em nível global, porque não dizer que terra é uma grande matriz de vida, um lugar de solidariedade que transporta para outra dimensão, a cósmica que nos remete ao contexto de privilégios para utilizar de maneira vantajosa as duas educações, uma que é a ambiental e a outra uma educação para o desenvolvimento do ser como indivíduo e como sociedade.

Essas duas maneiras das práxis educativas sendo consolidada pode transformar a vida de uma pessoa ou de uma sociedade de um determinado território e trazer maior harmonia ser humano/natureza. Passa, assim, a existir de forma mais incorporada, possibilitando a adoção do desenvolvimento sustentável.

O que se pode chamar de desenvolvimento sustentável? Em meio ao desenvolvimento econômico capitalista, existem inúmeras citações de desenvolvimento sustentável. Segundo Poles e Rabinovici (2010, p. 18.):

[...]. Em meio a esse cenário de tensão surge o conceito de desenvolvimento sustentável, que doravante será tratado pela sigla (DS), que pode ser entendido, basicamente, como aquele que busca uma harmonia entre desenvolvimento econômico e conservação ambienta, fazendo uso consciente dos recursos naturais e como baixos impactos socioambientais. O DS e a conservação do meio natural não podem ser vistos isoladamente, pois são intrínsecos ao conceito de sustentabilidade.

Não se pode pensar em desenvolvimento sustentável sem sustentabilidade, pois a autosustentabilidade é um princípio desse tipo de desenvolvimento econômico.

Desta forma, a Educação Ambiental deve fornecer caminhos para que o educando consiga refletir sobre o princípio desse desenvolvimento, considerado por muitos como um modelo a ser seguido, principalmente para os empreendedores que trabalham com o ecoturismo.

A sustentabilidade pode atingir vários territórios sejam eles locais, regionais, nacionais ou internacionais. Isso vai depender do grau de importância que a sociedade de um determinado território dá a esse modelo de sustentabilidade. Para Satterthwaite (2004, apud BARBOSA, 2008, p.4.), o desenvolvimento sustentável (sustentabilidade) é "a resposta às necessidades humanas nas cidades com o mínimo ou nenhuma transferência dos custos da produção, consumo ou lixo para outras pessoas ou ecossistemas, hoje e no futuro". 


\section{O Ecoturismo ou turismo em áreas naturais e sua função socioeconômica.}

O ecoturismo ou turismo em áreas naturais tem crescido muito nos últimos anos, impulsionado pela ideia de desenvolvimento sustentável. Segundo Mckercher (2002), o turismo de natureza abrange o ecoturismo, o turismo de aventura, o turismo educativo, o turismo sustentável e outras formas de turismo praticados ao ar livre de maneira alternativa. Para facilitar a compreensão do mercado de turismo, toda a abrangência de turismo em áreas naturais (rural) acabou sendo intitulado de ecoturismo, como define o Ministério do Turismo Brasileiro:

O Ecoturismo possui entre seus princípios a conservação ambiental aliada ao envolvimento das comunidades locais, devendo ser desenvolvido sob os princípios da sustentabilidade, com base em referenciais teóricos e práticos, e no suporte legal. 0 desenvolvimento sustentável é um conceito que visa harmonizar o crescimento econômico com a promoção da igualdade social e preservação do patrimônio natural, garantindo que as necessidades das atuais gerações sejam satisfeitas sem, contudo, comprometer o atendimento às necessidades das gerações futuras. (BRASIL, Ministério do Turismo, 2010, p. 11).

Manter o desenvolvimento econômico e social e o equilíbrio ecológico deve sempre ser levado em consideração no ecoturismo. O uso de maneira racional e equilibrada do meio natural deve ser a base para a promoção do desenvolvimento sustentável. Pode-se destacar que, para o Ministério do Turismo:

... os princípios e os critérios para o desenvolvimento do segmento devem considerar a gestão socioambiental dos recursos naturais, para que os impactos positivos do Ecoturismo sejam maximizados, e os negativos sejam minimizados na esfera ambiental, social e econômica, em especial aos que estão relacionados aos sítios turísticos naturais no Brasil, e àqueles relacionados às Unidades de Conservação que permitem a visitação pública (BRASIL, MINISTÉRIO DO TURISMO, 2010, p. 16).

Destaca-se que o ecoturismo segue sempre a lógica de: utilização sustentável do patrimônio natural e cultural, a promoção do bem estar populacional, incentivo à conservação do patrimônio natural e cultural e a busca de uma consciência ambientalista pela interpretação do ambiente e o desenvolvimento econômico.

\section{Educação e Ecoturismo: a junção para o desenvolvimento sustentável.}

Embora o turismo venha ganhando destaque em todo território nacional e tenha o potencial de ser fonte de geração de grande parte de nossa riqueza, o tema ecoturismo ainda é pouco difundido nos livros pedagógicos e nas salas de aulas.

A educação para o ecoturismo não é ministrada regularmente em salas de aulas da Educação Básica brasileira, pois o tema ecoturismo vem ganhando mais destaque apenas nos últimos quinze anos. Cabe ressaltar que: 
Em 1999 foi instituída a Política Nacional de Educação Ambiental (PNEA) prevendo-se que a sociedade como um todo tem direito à Educação Ambiental, mencionando-se que o ecoturismo deve ser incentivado como uma das formas de Educação Ambiental nãoformal. De acordo com o PNEA, a Educação Ambiental não-formal são ações e práticas educativas voltadas à sensibilização da coletividade sobre as questões ambientais e à sua organização e participação na defesa da qualidade do meio ambiente (BRASIL, 2005) (BACCHI, 2013, p. 28).

A educação para o ecoturismo deve priorizar o território local e valorizar o uso racional, garantindo renda e preservação dos recursos naturais. $E$ esse modelo de educação deve ser pautado no equilíbrio ambiental e na consciência do uso sustentável desses recursos. Barcelos (2012) destaca que a contribuição da Educação Ambiental na edificação da justiça social e ecológica, desafia inventar novas metodologias em espaços de convivência a partir da solidariedade e cooperação dos indivíduos.

Segundo Sachs (1993), todo planejamento de desenvolvimento precisa levar em conta, simultaneamente, as seguintes cinco dimensões de sustentabilidade: social, econômica, ecológica, espacial e cultural. É dentro dessa estratégia que devemos elaborar o desenvolvimento sustentável do ecoturismo.

\section{Da interpretação ambiental no Ecoturismo}

Antes de se adentrar no conjunto de elementos linguísticos, formadores do presente título, naquilo que diz respeito à interpretação ambiental no ecoturismo, mister se faz, separar em princípio tais elementos, vez que, cada termo tem em si um conjunto de informações, definições e princípios. Desta forma, para fins didáticos, trabalhar-se-á elemento por elemento, para ao final condensá-los no título como um todo.

\section{Interpretação}

A expressão ou elemento linguístico formado pela palavra 'interpretação', pode referendar a lição de Bastos (1999), quando à cerca da interpretação e a título de noção introdutória da referida expressão, tem-se: "interpretar é atribuir um sentido ou um significado a signos ou a símbolos, dentro de determinados parâmetros" (BASTOS, 1999. Pg. 17)

Neste mesmo passo, Streck (2003, p.93), afirma, com base em suas pesquisas e outras obras que lhe referendam que "interpretar é a busca do esclarecimento, do significado verdadeiro de uma expressão; é extrair de uma frase, de uma sentença, de uma norma, tudo o que na mesma se contém".

Tem-se, portanto, que o termo ou expressão 'interpretação' contém em si a necessidade de um objeto sobre o qual debruçará uma ação, com fins de dele extrair seu efetivo sentido ou significado.

Desta forma, o termo ou elemento formado pela palavra 'interpretação' não se resolve em si mesmo, ao passo que sua verdadeira e precípua missão é extrair 
de outro ou outros elementos linguísticos ou não, uma significância. Isto posto, deve vir associado a outro elemento o qual será seu objeto.

No presente estudo, a interpretação pautar-se-á por dois objetos cujos termos são: 'ambiental e ecoturismo', haja visto que um termo se encontra inserido no outro, que para fins do resultado final convergirá a 'interpretação ambiental no ecoturismo'.

\section{A expressão 'Ambiental'}

Este segundo elemento linguístico de análise no presente trabalho será apresentado como a expressão meio ambiente, muito embora, alguns pesquisadores do assunto, compreendam que as expressões meio e ambiente são redundantes. Assim leciona Beltrão (2014, p. 5), quando em sua obra diz:

A expressão meio ambiente, que historicamente passou a ser utilizada no Brasil, é claramente redundante. "Meio" e "ambiente" são sinônimos, designam o âmbito eu nos cerca, o nosso entorno, onde estamos inseridos e vivemos.

Entretanto, Milaré (2015, p. 138) defende que os vocábulos são distintos os, quando assim se manifesta:

Tanto a palavra meio como o vocábulo ambiente passam por conotações diferentes, quer na linguagem científica, quer na vulgar. Nenhum desses termos é unívoco (detentor de um significado único), mas ambos são equívocos (mesma palavra com significados diferentes). Meio pode significar aritmeticamente, a metade de um inteiro; um dado contexto físico ou social; um recurso ou insumo para alcançar ou produzir algo. Já ambiente pode representar um espaço geográfico ou social, físico ou psicológico, natural ou artificial.

Muito embora tal crítica se mostre pertinente à cientificidade das obras literárias e outros trabalhos de cunho científico, tem-se usado um termo associado ao outro, e por isso no presente trabalho aceita-se o termo meio ambiente, mesmo reconhecendo que existem essas visões contraditórias.

Outra contribuição de Beltrão (2014, p. 6) é quando cita a Lei 6.938/81, a qual em seu artigo 3ํinciso I, define meio ambiente com o seguinte texto: "conjunto de condições, leis, influências e interações de ordem física, química e biológica, que permite, abriga e rege a vida em todas as suas formas".

Ocorre que, para melhor compreender meio ambiente, indispensável analisalo sob ao menos três vieses, ou prismas que são: natural ou físico, artificial e cultural. 


\section{Meio Ambiente Natural ou Físico}

Assim é denominado o ambiente que existe e subsiste por si só, ou seja, sem a interferência humana. Nesse conjunto de elementos pode-se citar como parte integrante do meio ambiente a água, o ar, a atmosfera, o subsolo, a fauna, a flora, bem como toda biodiversidade que coexiste no sistema.

Ratifica tais apontamentos a doutrina de Fiorillo (2010, p. 71), quando em sua obra, acerca do meio ambiente natural, assim se manifesta:

O meio ambiente natural ou físico é constituído pela atmosfera, pelos elementos da biosfera, pelas águas (inclusive pelo mar territorial), pelo solo, pelo subsolo (inclusive os recursos minerais), pela fauna e flora. Concentra o fenômeno da homeostase, consistente no equilíbrio dinâmico entre os seres vivos e meio em que vivem.

Desta maneira, aceita-se a noção que o meio ambiente natural é aquele no qual não houve a intervenção humana.

\section{Meio Ambiente Artificial}

Nesta classificação, o meio ambiente é considerado artificial quando tem necessariamente a intervenção humana, e encontra-se para muitos textos que lidam com os aspectos urbanos, vez que nesses espaços é que se vê as edificações em uma maior escala. Está, portanto, vinculado às cidades. Beltrão (2014, p. 7) defende ser o meio ambiente artificial todo aquele no qual se "compreende o espaço urbano construído, abrangendo o conjunto de edificações...".

Desta feita, a compreensão do meio ambiente artificial é aquele sobre o qual o ser humano modificou, não precisando necessariamente encontrar-se nos espaços meramente urbanos. Como define o autor, ocorre também no meio rural quando é modificado, deixando, portanto, de ser natural para tornar-se artificial ou misto.

\section{Meio Ambiente Cultural}

Nestes espaços, verificam-se, como no meio ambiente artificial, a conduta ou ação humana. Entretanto, este daquele difere no sentido de que no meio ambiente cultural as intervenções humanas são de caráter material ou imaterial e dizem respeito a um valor imaterial destinado à cultura de um povo ou grupo para fins de preservar ou conservar sua identidade ou a memória de elementos físicos. Tem-se nesse quesito a manipulação ou transformações de matérias primas de acordo com as diferentes tradições e costumes, mesmo que de cunho religioso.

Desta forma, tais ações se integram a outros bens valorados, como afirma o Prof. José Afonso da Silva: "o meio ambiente cultural é integrado pelo patrimônio histórico, artístico, arqueológico, paisagístico, turístico, que embora artificial, em regra como obra do homem, difere do anterior (que também é cultural) pelo sentido de valor especial' (SILVA apud FIORILLO, 2010, p. 73). 
Existem outras classificações como o meio ambiente do trabalho ou escolar, entre outros. Entretanto, este texto se restringiu às três definições apresentadas para não correr o risco de desviar-se do foco da interpretação ambiental no ecoturismo.

\title{
Ecoturismo
}

Outro campo sobre o qual este trabalho recaiu juntamente com a interpretação é o 'ecoturismo'.

A definição de tal expressão, não se tem mostrado tarefa fácil, vez que data de décadas recentes. Entretanto, Bezerra (s/d) reforça que tal expressão encontrase mais evidenciada nos anos 1980, como menciona:

\begin{abstract}
Na década de 1980, põe-se em evidência a expressão Ecoturismo utilizado em termos práticos, como atividade turística realizada em ambientes naturais cujo diferencial era a valorização das comunidades locais. Com o aumento das práticas intituladas de Ecoturismo registra-se nas décadas seguintes uma discussão que ganha importância nos debates da comunidade acadêmica, governo e ONG's. Tais debates ocorreram na perspectiva da elaboração de uma definição concreta para o termo Ecoturismo com seus princípios e características. Mas, entretanto, mesmo com a prática do Ecoturismo em ambientes naturais e em comunidades percebe-se ainda a inexistência de clareza quanto a definição cientifica deste termo (BEZERRA, s/d, acesso em 21 jan. 2019).
\end{abstract}

Entretanto, para não deixar ao largo tal mister, tem-se definido por ecoturismo ou como outros preferem, o turismo ecológico, como sendo:

\begin{abstract}
... segmento da atividade turística que utiliza, de forma sustentável, o patrimônio natural e cultural, incentiva sua conservação e busca a formação de uma consciência ambientalista por meio da interpretação do ambiente, promovendo 0 bem-estar das populações". A definição acima é dada pelo Ministério do Meio Ambiente em conjunto com o EMBRATUR - Instituto Brasileiro de Turismo e segue aquela criada pela Sociedade Internacional de Ecoturismo (TIES ou The International Ecotourism Society) (OECO. Acesso em 21/01/2019.)
\end{abstract}

Verifica-se dessa forma que a definição do referido termo 'ecoturismo' é utilizado por diversos atores, tanto em seara nacional como internacional, congregando análise de agentes públicos e privados que faz parte de sua definição.

Isto posto, se faz necessário realizar uma busca por definições adequadas para melhor compreensão sobre o objeto de análise daquilo que se propõe conhecer. Assim, será possível se dar a melhor interpretação ao conjunto de elementos referentes ao ecoturismo, que também deverá passar pela educação, que deve introduzir as temáticas pertinentes aos aspectos mencionados em todos os 
níveis do saber, assim como nas famílias e sociedade em geral, haja vista, a necessidade de mudar-se a cultura do uso inconsequente do meio natural, tornandoo um bem coletivo e protegido para as atuais e para as futuras gerações.

\section{Considerações Finais}

No presente trabalho pôde-se verificar o quão importante é a real compreensão dos elementos linguísticos a formar uma oração, visando ser compreendida por todos.

Não basta uma superficial noção do que se entende por ecoturismo e sua relação e correlação com outras áreas do saber.

É inegável a necessidade de uma efetiva participação coletiva de todos os agentes, sejam da esfera pública ou privada, vez que o principal dilema é a compreensão e importância da proteção do meio ambiente natural e cultural, que são as bases das ações do ecoturismo.

Vê-se, portanto, que sem sombra de dúvidas, é pela educação em todas as suas etapas que haverá uma efetiva mudança na compreensão da importância que deve ser dada ao meio ambiente, frente às políticas empreendedoras de exploração com fins econômicos ou não desses espaços.

Para tanto, um real entendimento perpassa pela forma como interpretamos linguisticamente esses espaços e como o definimos, para que, de forma mais íntima se possa melhor conhecer e discutir sobre o que é o ecoturismo.

\section{Referências}

BACCHI, R. A Educação Ambiental no Ecoturismo e no Turismo de Aventura: estudo de caso do Parque Estadual da Serra do Mar, Núcleo Santa Virgínia (SP). Dissertação (Mestrado). Escola Superior da Agricultura “Luiz de Queiroz”, Centro de Energia Nuclear na Agricultura, 2013.

BARBOSA, G,S, O desafio do desenvolvimento sustentável. Revista Visões. 4a edição. № 4. Vol. I. jan/jun 2008. Rio de Janeiro.

BARCELOS, V. Educação Ambiental: sobre princípios, metodologias e atitudes. 4.ed. Petrópolis: Vozes, 2012.

BASTOS, C.R. Hermenêutica e interpretação constitucional. $2^{a}$ edição. Editora IBDC. 1999. São Paulo.

BEZERRA. G.S. Os fundamentos teóricos-conceituais do Ecoturismo.
Disponível $<$ http://observatoriogeograficoamericalatina.org.mx/egal12/Teoriaymetodo/Conceptu ales/22.pdf>. Acesso em: 21 jan. 2019.

BRANCALIONE, L. Educação Ambiental: Refletindo Sobre Aspectos Históricos, Legais E Sua Importância No Contexto Social. Instituto de Desenvolvimento Educacional do Alto Uruguai - IDEAU. Revista de Educação do Rei, v.11. n.23 janeiro - junho. 2016.

BRASIL, MINISTÉRIO DO TURISMO. Ecoturismo: orientações básicas. Ministério do Turismo, Secretaria Nacional de Políticas de Turismo, Departamento de 
Estruturação, Articulação e Ordenamento Turístico, Coordenação Geral de Segmentação. 2. ed. - Brasília: Ministério do Turismo, 2007.

FIORILLO, C.A.P. Curso de direito ambiental brasileiro. $11^{a}$ edição. Saraiva. 2010. São Paulo.

MCKERCHER B. Turismo de Natureza: planejamento e sustentabilidade. São Paulo: Contexto, 2002.

MILARÉ, E. Direito do ambiente. 10ª edição. Revista dos Tribunais. 2015. São Paulo.

OECO. O que é Ecoturismo. Disponível em: <https://www.oeco.org.br/dicionarioambiental/28936-o-que-e-ecoturismo/> Acesso em: Acesso em 21 jan. 2019.

POLES, G.; RABINOVICI, A. O ambientalismo, o turismo e os dilemas do desenvolvimento sustentável. In: NEIMAN, Z.; RABINOVICI, A. (Orgs).Turismo e meio ambiente no Brasil. Barueri, SP: Manole, 2010. pp. $1-24$.

SACHS, I. Estratégias de transição para o século XXI. In: BURSZTYN, M. Para Pensar o Desenvolvimento Sustentável. São Paulo: Brasiliense, 1993.

SATTERTHWAITE, D. Como as cidades podem contribuir para o Desenvolvimento Sustentável. In: MENEGAT, R.; ALMEIDA, G. (org.). Desenvolvimento Sustentável e Gestão Ambiental nas Cidades: Estratégias a partir de Porto Alegre. Porto Alegre: UFRGS Editora, 2004.

STRECK, L.L. Hermenêutica jurídica e $(\mathbf{m})$ crise: uma exploração hermenêutica da construção do Direito. 4⿳亠丷a edição. Livraria do Advogado. 2003. Porto Alegre.

César Floriano de Camargo: Universidade Federal do Tocantins, Palmas, TO, Brasil.

E-mail: cesarcamargo.adv@live.com

Link para o currículo Lattes: http://lattes.cnpq.br/1935368235280074

Silmar Cardoso Araújo Coelho: Universidade Federal do Tocantins, Palmas, TO, Brasil.

E-mail: silmarcardoso21@hotmail.com

Link para o currículo Lattes: http://lattes.cnpq.br/0898488356609257

Data de submissão: 09 de março de 2019

Data de recebimento de correções: 11 de novembro de 2020

Data do aceite: 11 de novembro de 2020

Avaliado anonimamente 